\title{
POLUIÇÃO DE CÓRREGO POR ÁGUA DE RODOVIA E FONTES DOMICILIARES EM CRAVINHOS, SP ${ }^{1}$
}

\author{
Elias Antonio Vieira \\ Dr., Pesquisador do LabDES, UNESP, Franca/SP \\ Avenida Eufrázia Monteiro Petráglia, 900. CEP: 14409-160 - Franca - SP \\ evieira371@gmail.com
}

\section{RESUMO}

Este artigo trata do procedimento empregado por seu autor na avaliação de um caso de contaminação de recursos hídricos em Cravinhos (SP), em discussão judicial pelas partes. 0 método empregado constituiu-se de levantamento bibliográfico e da análise da documentação do processo judicial. O objetivo do trabalho é subsidiar os interessados no entendimento dos impactos ambientais que podem ser transformados em disputas judiciais. Os resultados do caso estudado permitem deduzir que as fontes geradoras da poluição têm responsabilidade compartilhada dos impactos ambientais e suas soluções.

Palavras-chave: Impactos ambientais. Contaminação. Recursos hídricos. Responsabilidade compartilhada

\begin{abstract}
STREAM OF WATER POLLUTION OF HIGHWAY AND DOMESTIC SOURCES IN CRAVINHOS, SP: This article deals with the procedure employed by the author in evaluating a case of it contamination of water resources in Cravinhos (SP), under judicial discussion by the parties. The method used consisted of a literature review and analysis of documentation of legal proceedings. The aim of this work is to support those interested in understanding the environmental impacts that can be transformed into legal disputes. The results of the case study can be derived that the sources of pollution have shared responsibility for environmental impacts and solutions.
\end{abstract}

Keywords: Environmental impacts. Contamination. Water resources. Shared responsibility.

\section{INTRODUÇÃO}

O que contribui para o ingresso de resíduos e rejeitos contaminantes no sistema de drenagem de água pluvial da área urbana em bairro periférico e do trecho da Rodovia Estadual de Cravinhos? Quais os fatores que podem contribuir com a contaminação de manancial hídrico a partir desse sistema de drenagem de água pluvial? Que impactos ambientais podem resultar desse processo e qual a medida preventiva a ser adotada?

\footnotetext{
${ }^{1}$ O autor agradece o apoio recebido da FAPESP - Fundação de Amparo à Pesquisa do Estado de São Paulo para um projeto maior que também permitiu a realização deste trabalho.

http://cascavel.ufsm.br/revistas/ojs-2.2.2/index.php/remoa
} 
Pois bem, estas são as questões problema, norteadoras dessa pesquisa, para as quais se levantaram dados visando fundamentar as respostas.

Com a finalidade de contextualizar a realidade espacial, social e econômica de Cravinhos, alvo do processo de contaminação de manancial hídrico por ingresso de resíduos e rejeitos contaminantes no sistema de drenagem de água pluvial analisado nesta pesquisa apresenta-se as seguintes informações:

O município citado (FIGURA 1) foi desmembrado de Ribeirão Preto, em 1897, e instalado no ano seguinte. $O$ fato de seu sítio ter sido uma fazenda em que havia pequenos cravos plantados originou o nome. Situa-se na latitude $21^{\circ} 20^{\prime} 25^{\prime \prime}$ Sul e longitude 47043'46" Oeste e altitude de 788 metros. Sua população estimada, em 2008, de 30.647 habitantes está distribuída em 26 lugares assim denominados: Alto das Acácias, Centro, Conjunto Habitacional Trajano Stella, Jardim Alvorada, Jardim Anhanguera, Jardim Bela Vista, Jardim das Acácias, Jardim Independência, Jardim Itapuã, Jardim Paulista, Jardim Primavera, Jardim Santa Cruz, Nova Cravinhos, Parque industrial Alvorada, Parque São Francisco, Parque São José, Residencial Jardim Santana, Sumaré, Vila Claudia, Vila Pio XII, Vila Santa Cecília, Vila Viegas e nos conjuntos habitacionais Francisco Castilho I e II, Itamarati, João Berbel, Osvaldo Luís Netto (WIKIPÉDIA, 2011).

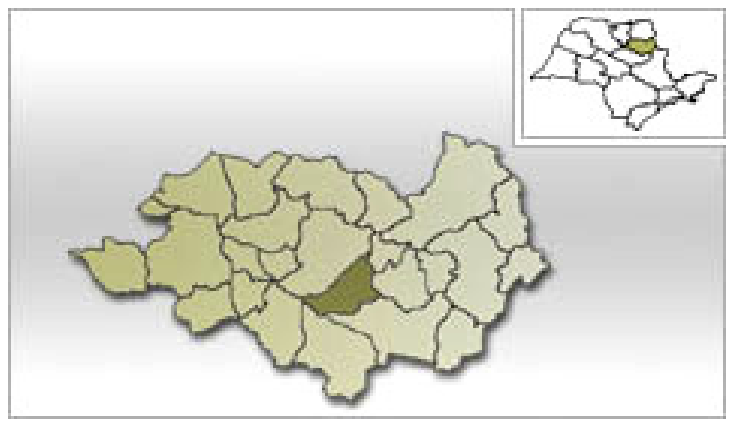

Figura 1. Localização de Cravinhos no na região de Ribeirão Preto (SP). Fonte: SEADE (2011)

O nome do bairro, da rodovia e dos responsáveis pelos fatos analisados como objeto do presente artigo foi substituído por razões éticas.

Outros dados da realidade da população de Cravinhos, em 2010, comparados aos do país, citados entre parêntesis, revelam melhor posição do município na quase totalidade dos quesitos. De acordo com o IBGE (2011), SEADE (2011) e WIKIPÉDIA (2011) a densidade demográfica de Cravinhos é de 91,3 habitantes por $\mathrm{km}^{2}(22,4)$; a mortalidade infantil, por mil habitantes, até um ano de 10,5 (29,6); expectativa de vida, em anos, de 74,3 (68); taxa de fecundidade, por mulher, de 2,3 (2,3); taxa de alfabetização de $90,96 \%(86,4 \%)$; rendimento médio do trabalho formal de R\$ $1.458,77$ (R\$ 1.550,26), e Índice de Desenvolvimento Humano - IDH de 0,815 (0,699).

As informações levantadas no presente estudo permitiram a comparação entre os dados oferecidos pelos responsáveis do sistema de drenagem e do manancial hídrico contaminado e as exigências normativas, e legais sobre a temática. A sigla LRCA é utilizada para identificar o bairro, e a sigla RAS o trecho da rodovia, e seus respectivos sistemas de drenagem de água pluvial. A escolha do objeto de estudo se deu pelos impactos sociais, ambientais e econômicos que o manejo errado de águas pluviais pode causar. 
Portanto, a finalidade deste estudo é apresentar subsídios, aos interessados no assunto, para entendimento dos fatores contribuintes com os impactos ambientais originados nos sistemas de drenagem, já citados, e induzir reflexões sobre possíveis medidas para sua prevenção.

Para tanto, a pesquisa se conduziu através de levantamentos bibliográficos, com apoio de manuais e sítios eletrônicos, da rede mundial de computadores relacionados ao seu escopo. De tal modo se percorre diversas etapas. Inicialmente fornece dados sobre a legislação e as normas sobre drenagem e saneamento básico. Em seguida demonstra os resultados da análise dos documentos oferecidos pelas partes responsáveis dos sistemas de drenagem de água pluvial.

Pela visita técnica realizada pelo autor desta pesquisa num sistema de dispositivos de contenção de água pluvial (bacia de amortecimento) instalado noutro bairro, no mesmo município, se verificou uma estreita relação entre cumprimento rigoroso das diretrizes legais, e normativas, ao bom funcionamento dos sistemas de drenagem. 0 descumprimento dessas diretrizes gera impactos sociais, ambientais e econômicos.

Diante disso, e tendo em vista os riscos associados aos impactos já relatados, na análise da documentação fornecida pelos responsáveis dos locais LRCA e RAS o pesquisador se esforçou em ponderar todos seus impactos positivos e negativos.

Portanto, o limite do presente estudo é conhecer o que contribui para o ingresso de resíduos e rejeitos contaminantes no sistema de drenagem de água pluvial da área urbana em bairro periférico e do trecho da Rodovia Estadual de Cravinhos. E, também, quais os fatores que podem contribuir com a contaminação de manancial hídrico a partir desse sistema de drenagem e que impactos ambientais podem resultar do processo e qual a medida preventiva a ser adotada.

Este trabalho tem por objetivo levantar, e analisar, dados principais sobre a documentação fornecida pelos responsáveis dos locais LRCA e RAS em comparação com a legislação, e as normatizações que Ihe são pertinentes visando buscar respostas aos problemas levantados.

A escolha do objeto de estudo desta pesquisa justifica-se por três motivos principais. 0 primeiro é o fato de as relações sociais, ambientais e econômicas, no atual momento histórico, orientado pelo capitalismo, terem as atividades produtivas em geral, inclusive de concessionárias de rodovias e construções de conjuntos de casas por empreendedores imobiliários, como parte fundamental à sua reprodução. O segundo baseia-se na necessidade de se produzir, e disseminar, conhecimento para facilitar o controle social sobre os impactos de diversas naturezas, e magnitudes, caso tais atividades não sejam conduzidas em conformidade com as normas técnicas e legais. E o terceiro leva em consideração o fato de as concessionárias de serviços públicos, e os empreendedores imobiliários, nem sempre apresentarem a documentação e ou executarem os serviços de manutenção adequados às normatizações.

\section{MÉTODO E TÉCNICA}

Em relação ao método, a pesquisa foi delineada através de seus objetivos, dos procedimentos de coleta de dados, e do foco de abordagem (ANDRADE, 2001). Portanto, sua classificação quanto aos objetivos é exploratória, visto que se propõe a fornecer uma visão geral, do tema pesquisado, podendo facilitar a formulação de novos problemas, e hipóteses, em pesquisas futuras. Quanto ao procedimento, ou seja, o modo pelo qual se coletaram os dados é 
bibliográfico, pois, se propôs levantar dados da produção científica existente em artigos, leis, manuais e normas técnicas, teses, entre outros. No tocante à abordagem do problema, a pesquisa é qualitativa (VERGARA 1997). Nesta última classificação, a pesquisa se restringe a verificar a conformidade da documentação apresentada pelos responsáveis dos locais LRCA e RAS em relação às normatizações em vigor.

Quanto à técnica da pesquisa, em primeiro lugar se obteve os documentos dos responsáveis pelos locais LRCA e RAS. Em seguida se levantaram os conteúdos no formado eletrônico, através de sítios de busca, nas páginas da rede mundial de computadores, que apresentavam resultados de pesquisas sobre o tema. Nessa etapa foram pesquisadas frases ou palavras-chave relacionadas às leis, manuais, normas e resoluções sobre sistema de drenagem, reservatório de detenção de cheias urbanas (bacia de amortecimento), saneamento básico, e contaminação de manancial hídrico. E, por último se fez visitas em campo para comparar os dados dos documentos com a realidade.

\section{Impactos ambientais do sistema de drenagem de água pluvial em área urbana} ambiental:

O artigo 1ำ da Resolução CONAMA no 1/1986 assim define o conceito de impacto [...] considera-se impacto ambiental qualquer alteração das propriedades físicas, químicas e biológicas do meio ambiente, causada por qualquer forma de matéria ou energia resultante das atividades humanas que, direta ou indiretamente, afetam: I - a saúde, a segurança e o bem-estar da população; II - as atividades sociais e econômicas; III - a biota; IV - as condições estéticas e sanitárias do meio ambiente; $V$ - a qualidade dos recursos ambientais. (CONAMA, 1986 p.1)

A solução dos impactos ambientais provocados pelas cheias de áreas urbanas, por sua vez, estaria na aplicação de sistemas de drenagem chamados modernos ou sustentáveis, cujo modelo é assim definido: "os novos desenvolvimentos [urbanos] não podem aumentar a vazão de pico das condições naturais (ou prévias) - controle da vazão de saída; planejar o conjunto da bacia para controle do volume; evitar a transferência dos impactos para jusante" (PARKINSON et. al 2003 p. 8). No entanto estes autores identificaram uma dificuldade fundamental para implantar esse modelo em países em desenvolvimento, como é o caso do Brasil:

[...] inadequação dos recursos alocados na drenagem urbana. Essa inadequação se manifesta tanto na insuficiência de investimentos, o que se reflete na fragilização da estrutura organizacional e nas deficiências da infra-estrutura da drenagem urbana, como também, na descontinuidade de fluxos financeiros, ou seja, há freqüentemente a paralisação de obras e grandes deficiências nos programas de manutenção (PARKINSON et. al 2003 p. 8).

\section{Análise da documentação dos sistemas de drenagem dos locais LRCA e RAS de Cravinhos (SP)}

A análise dos documentos permitiu inferir que o sistema de drenagem do local RAS existia desde a época que seu gerenciamento estava sob responsabilidade direta do órgão responsável do governo do Estado de São Paulo. 
Esta afirmação justifica-se pelo seguinte fato. O empreendedor imobiliário que construiu um conjunto de casas de padrão popular, então proprietário do local LRCA, firmou com o órgão responsável pela rodovia, um termo de compromisso, para instalar tubulação de travessia subterrânea num trecho para destinar águas pluviais oriundas da rede de galerias das casas e adjacências.

É forçoso advertir, com o devido respeito às partes envolvidas que, já nessa época, se fazia indispensável projetar o aumento da concentração e vazão de água no sistema, e sua solução, em virtude de processo de expansão de infra-estrutura urbana, e alterações no uso e ocupação do solo nessa região da cidade.

Importa elucidar que desde a década de 1970 estavam disponíveis as técnicas compensatórias para sanar problemas de drenagem urbana. Entre elas podem ser citadas a implantação de poços de infiltração, valetas de armazenamento, pavimentos porosos e micro reservatórios de retenção e infiltração, em nível de lote, conforme a vazão e geografia do lugar (ALVES E COSTA, 2007). Esses dispositivos deveriam ser integrados ao meio ambiente (área verde e ou institucional), permitindo reuso posterior da água, além de, no período de seca a área poder ser utilizada como bosque, estacionamento, praça de esportes, entre outras finalidades. Por isso requerem a implementação de plano de educação ambiental permanente a fim de garantir seu uso socioespacial correto, e seguro, à comunidade. Quanto à implantação das lagoas de amortecimento das águas do sistema de drenagem em questão, pelo responsável do local RAS é preciso assegurar a manifestação de sua conformidade às normatizações dos órgãos responsáveis do governo do Estado de São Paulo.

Fontes geradoras de poluição de água do local LRCA e contaminações da água coletada nos pontos 1, 2 e 3, do sistema de drenagem do local RAS, conforme laudo de análise

Nas visitas técnicas realizadas no percurso do sistema de drenagem existente no local RAS, inclusive nas três primeiras caixas de retenção de água localizadas na ligação das canaletas desse sistema, dentro do local onde situa o manancial hídrico que estaria contaminado e em trechos do local LRCA foram constatadas as seguintes ocorrências: a) escorre água pelas tubulações e canaletas, captadas à montante, de modo intermitente, mesmo em dia ensolarado, e sem chuva, com base no item anterior confirma-se que o sistema em questão também recebe águas usadas nos domicílios urbanos; c) a partir de identificação do percurso da água que escorria pela sarjeta se apurou que sua origem se dá em diferentes fontes geradoras e usos. Entre elas podem ser citadas a moradia residencial e as atividades econômicas. Na primeira verificou-se que:

(i) reusa água de lavagem de roupa para lavar o quintal;

(ii) lava o quintal e a calçada misturando-se à água as fezes de animais e aves (prática errada de usar o esguicho como vassoura); e

(iii) esvazia a piscina conduzindo a água para a sarjeta.

Na segunda, por sua vez, se apurou que:

(i) oficina mecânica e equipamento de lavagem de ônibus de transporte de trabalhadores rurais operam em desconformidade com a norma técnica que determina a implantação de sistema separador de óleo, lubrificante e detritos da água. Do mesmo modo não respeita a norma sobre 
acondicionamento e destinação correta de materiais contaminados por óleo, graxa etc. (estopa, embalagens, panos etc.); e

(ii) marmoraria que descarta, na sarjeta, água usada com aparência semelhante a leite, resultante da decantação de rejeito do processo de corte e acabamento de pedras decorativas entre outras.

Nesse caso é indispensável que as fontes de potencial de contaminação das águas pluviais apresentem documentação de conformidade de seus sistemas às normas do órgão responsável pela gestão das águas pluviais no município.

\section{Análise dos resultados do laudo fornecido pelo responsável do local RAS}

A análise dos parâmetros físico-químicos do líquido amostrado em comparação com os parâmetros de Valor Máximo Permitido (VMP), citado no laudo, permite inferir que sua classificação foi enquadrada na Classe 1 - águas doces, da Resolução CONAMA no 357 (CONAMA, 2005).

Portanto, não levou em conta a classificação dos corpos d'água do ponto de vista de seus usos preponderantes, conforme preconiza o artigo 3ㅇ da Resolução retro mencionada. No entanto, o laudo comprova a hipótese de que esse líquido é originário de fontes poluidoras como podem ser os domicílios e equipamentos urbanos, e a rodovia.

Nesse caso fica confirmada sua caracterização como efluente ou água poluída, cujo lançamento, no corpo d'água, deve cumprir o artigo 25 da Resolução CONAMA no 357.

O laudo também confirmou a presença de substâncias químicas potencialmente tóxicas, conhecidas por metais pesados (inorgânicos), e Poluentes Orgânicos Persistentes (POP), utilizadas como agrotóxico, herbicida, tratamento de madeira, processos industriais, entre outras finalidades, sendo exigido o manejo dos últimos em conformidade com o decreto federal $\mathrm{n}$ o 5.472/2005 (BRASIL, 2005).

Cumpre chamar a atenção para o fato de que algumas substâncias, classificadas como POP (exemplo: hexaclorobenzeno ou BHC e Clordano), além de outras, identificadas no laudo tem parâmetros acima do VMP.

Para fins de esclarecimentos vale dizer que a pesquisa bibliográfica visando identificar os usos de algumas substâncias encontradas nas amostras em níveis acima do VMP apresentou o seguinte resultado: a) Antrazina, presente na amostra do ponto 1 - herbicida geralmente utilizado pelo método químico de capina na eliminação de plantas invasoras da cultura do milho (BULA, $2011)$; b) Sulfeto $\left(H^{2} S\right)$, presente na amostra do ponto 2 - pode ter origem em meio natural e processos industriais como remoção química e ou lavagem de gases ácidos, sistemas de tratamento de efluentes, decapagens ácidas etc.(MAINIER; VIOLA, 2011); c) heptacloro epóxido (POP), encontrado na amostra do ponto 3 é um pesticida de uso restrito ao tratamento de algumas sementes (LSC, 2011).

No caso de substâncias potencialmente tóxicas, confirmada pelo laudo, é incorreto descartar a hipótese de sua geração ocorrer nas atividades econômicas ou não, sobretudo as adjacentes às vias marginais da rodovia dentro da bacia de contribuição. Todavia não se pode desconsiderar a hipótese de os veículos que trafegam pelas vias urbanas e na rodovia contribuir com o ingresso de substâncias contaminantes no sistema de drenagem tais como partículas do 
desgaste de pneus e pastilhas de freio; derrame de combustível e lubrificante, os quais podem fluir da pista de tráfego.

Já as características dos resíduos e rejeitos sólidos encontrados, em visita técnica, no sistema de drenagem (embalagens plásticas, restos de construção civil etc.), permitem entender que, sem levar em conta os quantitativos, suas fontes geradoras podem ser tanto os domicílios da área urbana como os usuários da rodovia.

Nesse caso, além de se recomendar o tratamento dos elementos químicos potencialmente tóxicos, já citados, é imperiosa a implantação de dispositivo para separar resíduos e ou rejeitos sólidos urbanos e substâncias de petróleo (óleo, graxas etc.) e componentes de veículos, da água pluvial, inclusive os gerados na rodovia (artigo 25 da Resolução CONAMA no 357).

Diante desses fatos, parece clara a responsabilidade compartilhada:

(i) das fontes geradoras;

(ii) do então proprietário do local LRCA e ou da Municipalidade;

(iii) e responsável pelo local RAS conforme Lei Federal № 12.305/2010 ou PNRS - Política Nacional de Resíduos Sólidos (BRASIL, 2010a). Portanto, a responsabilidade citada abrange a adequação do sistema de drenagem às normas e legislação, e correção do dano socioespacial, resultante da destinação dos efluentes ou água poluída, em desconformidade com a norma (artigo 25 da Resolução CONAMA no 357), na propriedade onde se localiza o manancial hídrico cujo proprietário reclama sua contaminação.

\section{Estudos hidrológicos da bacia de contribuição e cálculo do volume das lagoas de retenção de água pluvial}

O estudo apresentado pelo responsável do local RAS cotejado com a análise visual da área geográfica abrangida pela bacia de contribuição da água pluvial, durante visita técnica do autor da pesquisa, permite a inferência que se segue. A demarcação do trecho do local RAS, e o ocupado pela pista da rodovia sentido capital-interior, não correspondem à realidade e, por conseqüência, seu valor de contribuição parece inadequado.

Como se não bastasse, a falta do projeto executivo das lagoas, no lugar da folha de desenhos apresentada pelo responsável do local RAS, impossibilitou a checagem dos cálculos do estudo hidrológico apresentado. Diante disso, os resultados dos quantitativos dos volumes de precipitação, vazão etc. e sua relação com a capacidade operacional desse empreendimento não foram considerados.

De qualquer modo não justifica estabelecer grau de responsabilidade uma vez que, o sistema de drenagem situado no local RAS, já citado, serve em comum ao despejo das águas pluviais deste e do local LRCA. Neste caso, o autor desta pesquisa recomenda a aplicação do princípio da responsabilidade compartilhada, da Lei Federal $n=12.305 / 2010$ na adequação desse sistema e solução dos danos socioespaciais. 


\section{A realidade do sistema de drenagem dos locais LRCA e RAS}

Durante as visitas técnicas realizadas tanto no local LRCA como no RAS, se verificou que não há plano de gerenciamento do sistema de drenagem ou há, entretanto seus métodos e técnicas não resolvem, com eficiência, as causas que podem comprometer o funcionamento do sistema.

Os trechos visitados denotam ausência ou falta de concretização de ações ou recursos tais como:

(i) mobilização comunitária, educação ambiental e fiscalização das fontes geradoras quanto ao uso do sistema, sobretudo em relação à destinação de água servida; disponibilidade e capacitação de equipes técnicas e operacionais, da Municipalidade, dotadas de veículo e equipamentos apropriados;

(ii) fiscalização de conformidade técnica e legal das fontes geradoras, serviços de manutenção do sistema de drenagem e seu entorno, numa freqüência adequada a cada caso, visando à prevenção dos danos socioespaciais. Entre esses serviços podem ser citados: instalação de dispositivo de contenção e atividade de raspagem e ou coleta de sedimentos, resíduos e rejeitos sólidos (inclusive objetos domésticos e galhadas);

(iii) postos de entrega voluntária de recicláveis, roçadas e remoção de grama, capim e vegetação invasora; desobstrução de grelhas antes e depois das chuvas; limpeza de bueiros; remoção de restos de solo ou pavimento gerado nos serviços públicos de manutenção da rede de água e esgoto, e monitoramento e conservação da rede de esgoto.

\section{Considerações finais}

Os resultados conseguidos no presente estudo demonstram que é extensa a documentação exigida pelos órgãos públicos para identificar e definir a responsabilidade, sobre os impactos ambientais. E que os documentos apresentados, pelos responsáveis dos sistemas de drenagem, contém lacunas no que diz respeito aos aspectos normativos e legais.

Assim, as respostas às questões norteadoras da pesquisa são apresentadas conforme segue. Quanto a primeira e segunda questão da pesquisa há apenas uma causa determinante do ingresso de resíduos e rejeitos que, por efeito, atuam como contribuintes da contaminação no sistema de drenagem de água pluvial citado: a ausência ou ineficiência de plano de gerenciamento do sistema. No que diz respeito à terceira questão se constatou que até a data dos estudos realizados os responsáveis pela contaminação não haviam adotado nenhuma medida preventiva eficaz na mitigação do problema. É importante ressaltar que o presente estudo oferece opção de estratégias para contribuir na solução do impacto ambiental do local RAS.

Deste modo tem-se por expectativa que esta pesquisa possa subsidiar a adequação do sistema de drenagem citado às normatizações para prevenir os impactos ambientais. Além disso, alerta as autoridades e os responsáveis pela aprovação de loteamento e gestão de rodovias, para necessidade de reflexão sobre as exigências técnicas e legislativas aos futuros empreendimentos semelhantes ao que motivou esta pesquisa. 


$$
\text { VIEIRA, v(7), no 7, p. } 1503 \text { - 1511, MAR-JUN, } 2012 .
$$

\section{REFERÊNCIAS}

ALVES, F. A. O; COSTA, A. R. Estimativa de volume para reservatório de detenção no controle de cheias urbanas. I Simpósio de Recursos Hídricos do Norte e Centro-Oeste. Cuiabá (MT), 2007. ANDRADE, M. M. Introdução à metodologia do trabalho científico. São Paulo: Atlas, 2001. ARAUJO, P. R.; TUCCI, C. E. M.; GOLDENFUN, J. A. Avaliação da eficiência dos pavimentos permeáveis na redução de escoamento superficial. Instituto de Pesquisas Hidráulicas da UFRGS Porto Alegre (RS). Disponível em: <http://galileu.iph.ufrgs.br>. Acesso em: 13 nov. 2011.

BRASIL (UNIÃO) Casa Civil. Decreto no 5.472/2005. Promulga texto da Convenção de Estocolmo sobre poluentes orgânicos persistentes. Brasília, 2005.

Lei $n$ ㅇ 11.445/2007. Diretrizes nacionais para o saneamento básico. Brasília, 2007. Decreto $n$ 0 7.217/2010. Regulamento da política nacional de saneamento básico.

Brasília, 2010.

Lei Federal no 12.305/2010. Política nacional de resíduos sólidos - PNRS. Brasília: 2010a. CONAMA - Conselho Nacional do Meio Ambiente. Resolução CONAMA no 1/1986. Estudo de impacto ambiental. Brasília, 1986.

Resolução CONAMA no 357/2005. Classificação de corpos d'água, condições e padrões para lançamento de efluentes. Brasília, 2005.

BULA. Antrazina Atanor 50 SC. Disponível em: <http://www.agroimport.com.br.> Acesso em: 7 fev. 2011.

CRAVINHOS (MUNICÍPIO). Secretaria Municipal de Obras. Cópia de plantas da galeria de águas pluviais do Jardim Alvorada, do requerimento e da autorização de travessia de tubulação para escoamento de água em faixa de domínio do DER. Cravinhos, 2011.

LSC - LABORATÓRIO SÃO CAMILO. Heptacloro e heptacloro epóxido. Disponível em: $<$ http://saocamilolab.com.br/exames>. Acesso em 7 fev. 2011.

MAINIER, F. B.; VIOLA, E. D. M. O sulfeto de hidrogênio $\left(\mathrm{H}_{2} \mathrm{~S}\right)$ e o meio ambiente. Disponível em: $<$ http://www.aedb.br/seget/artigos05/261 H2S.pdf.>. Acesso em: 7 fev. 2011.

MINAS GERAIS (ESTADO). Secretaria de Meio Ambiente e Desenvolvimento Sustentável.

Orientações básicas para a drenagem urbana. Belo Horizonte, FEAM, 2006.

PARKINSON, J.; MILOGRANA, J.; CAMPOS, L. C.; CAMPOS, R. Drenagem Urbana Sustentável no Brasil. In: Workshop sobre drenagem urbana em Goiânia. Universidade Federal de Goiás. 7 de maio de 2003. Goiânia: UFG, 2003.

SÃO PAULO (ESTADO) Ministério Público. Promotoria de Justiça de Cravinhos. Inquérito Civil no 14/2003. Cravinhos, 2003.

SEADE - Fundação Sistema Estadual de Análise de Dados. Perfil municipal. Disponível em: $<$ http://www.seade.gov.br>. Acesso em 13 nov. 2011.

TOMAZ, P. Caixa de retenção de óleo e sedimentos. São Paulo, 2005. WIKIPÉDIA. Cravinhos. Disponível em: <http://pt.wikipedia.org>. Acesso em 13 nov. 2011. VERGARA, S. C. Projetos e Relatórios de Pesquisa em Administração. São Paulo: Atlas, 1997. 